\title{
Caractérisation des plantes médicinales à flavonoïdes des marchés de Douala (Cameroun)
}

\author{
Marie-Catherine KIDIK POUKA ${ }^{1}$, Jean-Pierre NGENE ${ }^{1}$, Charles Christian NGOULE ${ }^{1}$, \\ Patrice Brice MVOGO OTTOU ${ }^{2}$, Rosette Christelle NDJIB ${ }^{2}$, \\ Siegfried Didier DIBONG ${ }^{1,2,3^{*}}$ et Emmanuel MPONDO MPONDO ${ }^{1,2}$ \\ ${ }^{1}$ Département des Sciences Pharmaceutiques, Faculté de Médecine et des Sciences Pharmaceutiques, \\ Université de Douala, B.P. 2701 Douala, Cameroun. \\ ${ }^{2}$ Département de Biologie des Organismes Végétaux, Faculté des Sciences, B.P. 24157 Douala, Cameroun. \\ ${ }^{3}$ Département d'Aquaculture, Institut des Sciences Halieutiques, B.P. 2701 Douala, Cameroun. \\ *Auteur correspondant ; E-mail: didierdibong@yahoo.fr
}

\section{RESUME}

Les plantes à flavonoïdes constituent un atout majeur pour le maintien de la santé. Le présent travail a été conduit dans deux marchés de la ville de Douala afin de valoriser l'utilisation des plantes à flavonoïdes dans la médecine traditionnelle. Des enquêtes ethnobotaniques réalisées auprès de 40 vendeurs des plantes médicinales ont permis de recenser 75 espèces reparties en 73 genres et 42 familles dont la plus importante est celle des Fabaceae. Ces plantes comptent 50 ligneux et 25 herbacées, avec une prédominance d'espèces de forêt. Les espèces guinéo-congolaises sont les plus abondantes et le mode de dissémination majoritaire des diaspores est la zoochorie. Les plantes à flavonoïdes les plus utilisées sont : Combretum micranthum, Aloe vera, Ageratum conyzö̈des et Cylicodiscus gabonensis. Elles rentrent dans le traitement de 73 maladies parmi lesquelles, le paludisme, la fièvre typhoïde, les dermatoses, la jaunisse, le mal de reins, les coliques, le diabète, les maladies cardio-vasculaires et l'hypertension artérielle sont les plus importantes. Ces plantes apparaissent comme de puissants antioxydants et antiradicalaires. Ces propriétés dues à la présence de nombreuses molécules flavaniques, donnent à ces plantes une place de choix en phytomédecine.

(C) 2015 International Formulae Group. All rights reserved.

Mots clés : Flavonoïdes, enquête ethnobotanique, marché des Chèvres, marché Nkololoun, plantes médicinales, caractéristiques floristiques.

\section{INTRODUCTION}

Les relations entre les plantes et les hommes existent depuis l'antiquité (Din et al.,
2011). Les plantes, éléments vitaux de la diversité biologique servent essentiellement au bien être humain (Adjanohoun, 2000). 
L'homme, dans son environnement, a accordé un intérêt croissant pour l'étude des plantes médicinales et leur utilisation traditionnelle dans différentes régions du monde (Muthu et al., 2006). Cet intérêt a conduit aux enquêtes ethnobotaniques qui se sont avérées être l'une des approches la plus fiable pour la découverte de nouveaux médicaments (Koné, 2009). En effet, les plantes médicinales constituent des ressources précieuses pour la majorité des populations rurales en Afrique, car plus de $80 \%$ y recourent pour assurer les soins de première nécessité. En outre, la majeure partie des thérapies implique l'exploitation du principe actif des plantes médicinales (Biyiti et al., 2004 ; Dibong et al., 2011a ; Mpondo et al., 2012). De plus, ces plantes constituent des ressources inestimables pour l'industrie pharmaceutique (Awono et al., 2009). Par ailleurs, l'exploitation des produits forestiers non ligneux (PFNLs) est devenue une activité de plus en plus attrayante pour de nombreuses personnes démunies et sans emploi aussi bien en milieu rural qu'en milieu urbain (Priso et al., 2011).

L'inexistence des infrastructures sanitaires, la constante augmentation des prix des produits et prestations de santé, l'inaccessibilité aux médicaments génériques constituent un problème majeur pour les populations financièrement démunies. Les médicaments conventionnels, onéreux et souvent très toxiques ne constituent pas toujours un moyen efficace pour l'amélioration de la santé au Cameroun. C'est pourquoi la médecine traditionnelle apparaît comme l'alternative la plus appropriée pour combler les carences en besoins sanitaires dont les populations aspirent d'autant plus que ces dernières années, la phytothérapie par les plantes riches en polyphénols et principalement en flavonoïdes a connu un grand regain (Mpondo et al., 2012). Les plantes à flavonoïdes ont d'ailleurs montré qu'elles avaient des propriétés biologiques très importantes et très vastes. Ces espèces végétales d'aussi grande importance pour la santé des populations méritent d'être étudiées scientifiquement pour leur meilleure utilisation. Toutefois, bien que les travaux de Abdou Bouba (2009) et de Mpondo et al. (2012) aient pu relever le rôle joué par les plantes à flavonoïdes dans de nombreux processus de santé, les études permettant de les valoriser restent tout de même embryonnaires au Cameroun.

Le présent travail a pour objectif majeur de valoriser les plantes à flavonoïdes. Il se propose de fournir un état des lieux sur les bienfaits des plantes à flavonoïdes et une réflexion sur la vulgarisation de la médecine traditionnelle à base de ces plantes dans la ville de Douala.

\section{MATERIEL ET METHODES \\ Site d'étude}

Douala (latitude, $03^{\circ} 40^{\prime}-04^{\circ} 11^{\prime} \mathrm{N}$; longitude, $09^{\circ} 16^{\prime}-09^{\circ} 52^{\prime} \mathrm{E}$; altitude, $13 \mathrm{~m}$ ) a un climat qui appartient au domaine équatorial d'un type particulier dit «camerounien» qui se caractérise par deux saisons avec une longue saison de pluies (au moins 9 mois), des précipitations abondantes (environ $4000 \mathrm{~mm}$ par an), des températures élevées $\left(26,7{ }^{\circ} \mathrm{C}\right)$ et stables. La moyenne minimale de température à Douala pour 30 années (1961-1990) est de $22,6{ }^{\circ} \mathrm{C}$ en juillet et la moyenne maximale de température de $32,3{ }^{\circ} \mathrm{C}$ en février. L'humidité relative de l'air reste élevée toute l'année et voisine de 100\% (Din et al., 2008). Douala, chef-lieu de la région du Littoral, compte quatre départements : le Moungo, la Sanaga Maritime, le Nkam et le Wouri. Douala a environ 2,5 millions d'habitants et la croissance démographique n'est pas toujours 
suivie d'une augmentation des ressources économiques (Priso et al., 2011). La région du Littoral est un ensemble d'écosystèmes où se côtoient les forêts denses humides sempervirentes notamment la forêt dense humide sempervirente littorale entre 0 et 100 $\mathrm{m}$ d'altitude et la forêt dense humide biafréenne entre 100 et $500 \mathrm{~m}$ d'altitude (Letouzey, 1985), la mangrove, les marécages, la végétation ripicole, les agro écosystèmes et la végétation plus ou moins anthropisée. Ces écosystèmes terrestres et hydromorphes subissent d'énormes pressions anthropiques (pollution surtout en milieu urbain et déforestation en milieu périurbain) (Priso et al., 2011).

\section{Méthodes d'enquête}

Des prospections dans les marchés ont précédé les enquêtes effectuées dans les marchés spécialisés retenus. Ces prospections se sont faites au mois de juin 2013 dans neuf marchés de la ville de Douala, dans le but de retenir ceux spécialisés dans la vente des plantes médicinales. Deux marchés ont été retenus sur la base du nombre important de vendeurs, de leur disponibilité et du nombre de plantes médicinales vendu dans ces marchés. Il s'agit du Marché des Chèvres et du Marché Nkololoun. Un échantillon de 40 vendeurs, les plus accueillants et motivés pour la circonstance (soit 20 par marché) a été interviewé indépendamment du sexe, de l'âge et de l'ethnie. Chacun d'eux a fourni des informations sur l'utilisation dans la pharmacopée traditionnelle ou la pharmacopée populaire de 10 plantes.

L'enquête proprement dite s'est effectuée pendant la période allant du 07 au 21 juillet 2013. Elle était basée sur les interrogations directes en langues française ou locales. Pour chaque enquêté qui acceptait répondre aux questions et pour une maladie donnée, les informations ont été collectées selon un canevas standardisé inspiré des fiches Pharmel (Adjanohoun et al., 1989, 1994). Pour chaque indication thérapeutique, on relève avec soin les détails de la recette et on cherche dans la mesure du possible à voir la plante traitante. Ladite enquête s'est effectuée au moyen d'une fiche d'enquête portant des informations socio - économiques sur les vendeurs, les informations relatives aux plantes, aux molécules qu'elles renferment et aux maladies qu'elles soignent. Les étudiants du niveau $\mathrm{V}$ du Département de Biologie des Organismes Végétaux de la Faculté des Sciences de l'Université de Douala et ceux du niveau IV du Département de Sciences Pharmaceutiques de la Faculté de Médecine et des Sciences Pharmaceutiques de l'Université de Douala ont été mis à contribution pour ce travail dans le cadre des travaux pratiques et du travail personnel de l'étudiant. Ils ont été répartis en 04 groupes de 05 étudiants soient 10 personnes enquêtées par groupe. Dans chaque groupe, la présence d'au moins un étudiant appartenant à la tribu majoritaire du Marché a permis de communiquer et de réaliser sans difficulté majeure les enquêtes auprès des vendeurs sollicités. Les récoltes d'échantillons ont consisté à l'achat des organes végétatifs utilisés dans les recettes. Les informations sur le « diagnostic des maladies » (symptômes ou effets physiologiques) ont été recueillies auprès des médecins, infirmiers ou agents de santé locaux et complétées par la revue bibliographique (Adjanohoun et al., 1989, 2000).

Afin de corroborer les informations relatives aux plantes à flavonoïdes identifiées, une enquête retour s'est faite au mois d'août 2013. Au cours de cette enquête, il a également été relevé avec soin les détails de la recette pour chaque indication thérapeutique. 


\section{Apurement et saisie des données}

L'apurement des données consiste en la saisie des données d'enquêtes dans un tableau Microsoft Excel version 2007 sous forme de citations, en la détermination des caractéristiques floristiques et au regroupement des maladies. Par citation, nous entendons une ligne ou un enregistrement dans le tableur Excel reprenant pour une maladie citée, le nom de l'espèce végétale utilisée (nom commercial et/ou vernaculaire), le nom des espèces associées, l'organe végétal utilisé, le mode de préparation indiqué, la mode d'administration. On précise pour chaque citation, le nom de l'informateur, son sexe, son âge, sa fonction et son origine. Une citation peut aussi être assimilée à une recette. Pour une exploitation pratique des données et une harmonisation avec le système international, les problèmes de santé cités ont été regroupés suivant la classification statistique internationale des maladies et des problèmes de santé connexes version 2010 (WHO, 2010).

\section{Identification et caractérisation floristique des espèces \\ Identification des espèces}

La liste des plantes à flavonoïdes a été dressée à partir de la documentation botanique et ethnopharmacologique disponible dans les sites internet spécialisés (les plantes médicinales.net, hippocratus.com, espritsante.com...). L'identification des espèces s'est faite in situ sur le terrain, celles n'ayant pas pu être identifiées sur place ont été conservées dans l'herbier témoin et emportées à l'Herbier National du Cameroun pour identification. Cette identification s'est faite par simple comparaison des noms vernaculaires et/ou commerciaux obtenus dans les marchés, des échantillons de l'herbier témoin avec les données disponibles dans la littérature, les sites web (PROTAU4.ORG) et le matériel de référence disponible à l'herbier national du Cameroun où différentes flores africaines ont été consultées notamment celles du Gabon, du Congo et du Burundi. Elle a été approuvée par le Professeur Onana (Responsable de l'Herbier National du Cameroun) et les botanistes du Département de Biologie des Organismes Végétaux de la Faculté des Sciences de l'Université de Douala.

\section{Caractérisation floristique des espèces}

La florule (petite flore) (Betti, 2001) des PFNLs collectés a été caractérisée par: les types de distribution phytogéographiques, les types morphologiques, les types de biotopes, ainsi que les types et mode de dissémination des diaspores (Mullenders, 1954 ; Aubreville, 1962 ; White, 1986 ; Letouzey, 1985).

\section{Importance relative des plantes}

L'importance relative des plantes est déterminée par l'indice de performance des plantes citées. L'indice de performance (Ip) permet de mettre en évidence pour une maladie donnée, les usages les plus significatifs. Dans la comparaison entre la florule (petite flore) indiquée pour soigner une maladie donnée et la flore médicinale globale, l'hypothèse testée (hypothèse nulle au sens statistique) est que pour une indication thérapeutique (maladie) donnée, la liste des plantes citées pour son traitement résulte d'un tirage aléatoire dans la flore médicinale. Les proportions (pour les familles et les espèces) mesurées pour la flore médicinale sont considérées comme proportions théoriques (P2\%) et comparées à celles observées pour la florule citée contre la maladie choisie (P1\%). La différence observée (significative ou non dans le cadre de ce travail) entre ces deux proportions $(\mathrm{D}=\mathrm{P} 1-\mathrm{P} 2)$ indique si oui ou non l'échantillon analysé est un échantillon 
aléatoire de la flore médicinale; le sens de la différence permet de décider si le groupe étudié est préféré $(\mathrm{D}>0)$ ou rejeté $(\mathrm{D}<0)$. Les proportions utilisées ici sont des rapports de nombre de citations.

En considérant D $=0$ comme le seuil minimum de performance d'une espèce et 1 comme la valeur maximale, un indice de performance (Ip) est proposé à l'aide d'un barème arbitraire allant de 0 à 3 tel que (Betti, 2002) :

$I p=0$, si $\mathrm{D}<0$ : performance nulle;

$I p=1$, si $0 \leq \mathrm{D}<1 / 3$ : performance moyenne ;

Ip $=2$, si $1 / 3 \leq \mathrm{D}<2 / 3$ : performance élevée ;

$I p=3$, si $\mathrm{D} \geq 2 / 3$ : performance très élevée.

\section{Divergence des connaissances indigènes sur les traitements}

La divergence des connaissances indigènes sur les traitements des groupes de maladies est évaluée par le facteur de consensus d'utilisation (Informant consensus factor, ICF). Le facteur de consensus d'utilisation s'évalue en appréciant les accords entre les informateurs sur les traitements des groupes de maladies. Les groupes de maladies sont les suivants : Grossesse, accouchement et puerpéralité (GAP); Lésions traumatiques, empoisonnement et certaines autres conséquences des causes externes (LEA) ; Maladies de l'appareil circulatoire (MAC); Maladies de l'appareil digestif (MAD) ; Maladies de l'appareil génito-urinaire (MAG) ; Maladies de l'appareil respiratoire (MAR); Maladies endocriniennes, nutritionnelles et métaboliques (MEN) ; Maladies de l'œil et de ses annexes (MOA) ; Maladies du système ostéo-articulaire, des muscles et du tissu conjonctif (MOC) ; Maladies de l'oreille et de l'apophyse mastoïde (MOM) ; Maladies infectieuses et parasitaires (PAR); Maladies du système nerveux (MSN) ; Maladies tumorales (MT); Maladies virales (MV); Maladies de la peau et du tissu cellulaire sous-cutané (PTC); Maladies du sang et des organes hématopoïétiques et certains troubles immunitaires (SOI) ; Symptômes, signes et résultats anormaux d'examens cliniques (SSA). Afin d'apprécier les accords des informateurs sur les thérapies rapportées pour la catégorie d'utilisation, le facteur (degré) de consensus d'utilisation ou Informant Consensus Factor (ICF) a été calculé selon la formule suivante (Heinrich, 1998) :

$$
\begin{aligned}
& I C F=n_{u r}-n_{t /} n_{u r}-1 \\
& \mathrm{n}_{\mathrm{ur}}: \text { nombre de citation d'utilisation }
\end{aligned}
$$
de chaque catégorie ;

$n_{t}:$ le nombre total des espèces utilisées pour le même groupe de maladies.

L'ICF varie entre 0 et 1 . Une valeur faible (proche de 0 ) indique que les informateurs sont en désaccord sur les thérapies proposées pour le groupe de maladies concerné (Canales et al., 2005). Une valeur élevée (proche de 1) indique qu'il y a des critères de sélection bien définis pour les plantes citées dans la communauté et /ou qu'il y a échange d'information entre les personnes interrogées.

\section{RESULTATS}

\section{Informations sur les vendeurs enquêtés}

Les enquêtes effectuées dans les deux marchés ont permis de recenser 59 vendeurs dont 35 au marché des Chèvres et 24 au marché Nkololoun. Seuls 40 vendeurs ont été interviewés dont 20 au marché des chèvres (57\%) et 20 au marché Nkololoun $(83,33 \%)$. Le nombre de vendeur interrogé (40) est donc important comparé aux 59 vendeurs trouvés dans les marchés. Ces vendeurs sont des hommes ( $52 \%$ en moyenne) et des femmes 
(48\%). Ils appartiennent pour la plupart (72\% en moyenne) à la classe des adultes (29-59 ans) et sont en majorité ( $72 \%$ ) originaires de l'Ouest. Cependant, la question ici est de savoir si la liste de plantes à flavonoïdes obtenue est représentative de l'ensemble des plantes recensées. La courbe de l'évolution du nombre de plantes citées en fonction du nombre d'informateurs (interviewés) a été examinée (Figure 1).

Cette courbe révèle que l'augmentation du nombre d'informateurs ne contribue pas à augmenter le nombre de plantes au-delà d'un certain point.

\section{Caractéristiques floristiques des espèces à flavonoïdes recensées dans les marchés}

Les données d'enquêtes ont permis d'identifier 75 espèces à flavonoïdes appartenant à 42 familles subdivisées en 73 genres. La famille des Fabaceae est la plus représentée avec 7 espèces. Elle est suivie de la famille des Asteraceae (6 espèces); des Apocynaceae (4) et des Euphorbiaceae (4).

Ces espèces de plantes à flavonoïdes comptent 50 ligneux $(66,66 \%)$. Ce sont : Acacia catechu Willd., Adansonia digitata Linn., Alafia multiflora Stapf., Alchornea cordifolia (Schum. et Thonn.) Mùll. Arg., Alstonia boonei De Wild., Annona muricata Linn., Anthocleista vogelli Planch., Capsicum frutescens Linn., Carica papaya Linn., Cassia alata Linn., Chromolaena odorata (Linn.) R.M. King et Rob., Cinchona pubescens Vahl., Citrus limon (Linn.) Burm., Coffea arabica Linn., Cola acuminata Schott et Endl., Combretum micranthum G. Don., Cylicodiscus gabonensis Harms., Dacryodes edulis G. Don., Entandrophragma cylindricum Sprague, Eremomastax speciosa Hoschst., Erythrophleum suaveolens Guill. et Verr., Eucalyptus globulus Labill., Garcinia kola Heckel, Garcinia lucida Vesque, Gossypium barbadense Linn., Guibourtia tessmannii Harms., Hibiscus rosa sinensis Linn., Irvingia gabonensis Baill., Lantana camara Linn., Mammea africana Sab., Mangifera indica Linn., Manihot esculenta Crantz., Musanga cecropioides R. Br. et Tedlie, Panax ginseng C. A. Meyer, Pausinystalia Johimbe (K. schum) Pierre ex Beille, Persea americana Mill., Phragmantera capitata (Spreng) Balle, Piper guineensis Schum. et Thonn., Prunus Africana Hook. F., Psidium gojava Linn., Rauwolfia vomitoria Afzel., Ricinodendron heudelotti Baill., Syzygium aromaticum (Linn.) Merr. et L.M. perry, Tectona grandis Linn., Terminalia catapa Linn., Theobroma cacao Linn., Thymus vulgaris Linn., Viscum album Linn., Ziziphus lotus (Linn.) Lam.

Vingt cinq herbacées $(33,33 \%)$ ont été recensées. Ce sont: Achillia millefolium Linn., Ageratum conyzoüdes Linn., Alium cepa Linn., Alium sativum Linn., Aloe vera Linn., Arachis hypogaea Linn., Bidens pilosa Linn., Brassica oleracea Linn., Cleome ciliata Schum., Commelina benghalensis Linn., Costus afer Linn., Cucumis melon Linn., Cymbopogon citratus Tapf., Dissotis rotundifolia (Sm.) Triana, Eleusine indica (Linn.) Gaertn., Emilia coccinea G. Don., Euphorbia hirta Linn., Nicotiana tabacum Linn., Ocimum gratissimum Linn., Pulmonaria officinalis Linn., Ribes nigrum Linn., Solanum melongena Linn., Stevia rebaudiana Bert., Vigna unguiculata Linn., Zea mays Linn..

Parmi les ligneux, les arbres prédominent $(42 \%)$. Les herbacées comptent 11 herbes annuelles (15\%), 9 herbes vivaces $(12 \%)$ et 3 herbes bisannuelles $(4 \%)$ (Figure 2). 
Neuf types phytogéographiques ont été identifiés parmi les plantes à flavonoïdes recensées. Ce sont : 16 Guinéo-congolaises (22\%), 14 pantropicales (19\%), 11 d'Amérique (15\%), 8 d'Asie (11\%), 8 Afrotropicales (11\%), 7 d'Europe (9\%), 6 Soudano-zambéziennes $(8 \%), 3$ paléotropicales $(4 \%)$, et une cosmopolite $(1 \%)$ (Figure 3).

Les plantes à flavonoïdes inventoriées sont reparties dans 11 types de biotope : les milieux cultivés (33\%), la forêt secondaire $(16 \%)$, les rudérales $(15 \%)$, la forêt humide $(8 \%)$, la prairie $(8 \%)$, la forêt primaire $(7 \%)$, la savane humide $(7 \%)$ et la forêt de montagne (3\%) (Figure 4).

Les plantes à flavonoïdes inventoriées totalisent 7 types de diaspores. Les sarcochores sont les diaspores les plus présentes $(58,82 \%)$, suivies des sclérochores $(17,65 \%)$, des ballochores $(8,82 \%)$, des barochores $(7,35 \%)$ et des pogonochores $(4,41 \%)$. Le mode de dissémination des diaspores le plus répandu est la zoochorie $(60,29 \%)$. Il est suivi de l'anémochorie $(23,53 \%)$ et enfin de l'autochorie $(16,17 \%)$ (Figure 5).

\section{Organes végétatifs utilisés dans les recettes}

Diverses parties sont prélevées sur les plantes pour préparer les recettes médicamenteuses. Les feuilles sont majoritairement utilisées (51\% en moyenne) ; ensuite viennent les écorces $(27 \%)$; les racines et les rhizomes comptent pour $(7 \%)$ (Figures 6,7).

Plantes à flavonoïdes, maladies soignées et voies d'administration

\section{Maladies soignées}

Les plantes à flavonoïdes recensées rentrent dans le traitement de 73 maladies et problèmes de santé connexes citées par les vendeurs dont les plus importants en nombre de citations sont : Coliques (17) ; Dermatose (20) ; Diabète (18); Erythèmes fessiers (13) ; Hémorroïdes (13); Hypertension (13); Jaunisse (14); Mal de nerfs (12); Mal de reins (20), Mal d'estomac (17); Maladies Cardiovasculaires (11); Obésité (10); Paludisme (53) ; Purifie le sang (13) ; Syphilis (16) ; Toux (10) ; Typhoïde (28). Toutes ces maladies ont été regroupées en 17 grands groupes dont le plus important est celui des maladies infectieuses et parasitaires (PAR), il est suivi par celui des maladies de l'appareil digestif (MAD) (Figure 8).

\section{Divergence des connaissances dans les marchés}

$\mathrm{Au}$ total, 17 valeurs de facteur consensus d'utilisation ont été obtenues. La recherche du degré de consensus révèle que plusieurs catégories de maladies ont atteint des valeurs maximales de consensus. Seule la catégorie des Maladies du sang et des organes hématopoïétiques et certains troubles immunitaires (SOI) à la valeur nulle de consensus illustre l'importance relative des valeurs de consensus d'utilisation des plantes à flavonoïdes (Figure 9).

La voie orale est le principal mode d'administration des recettes à base des plantes à flavonoïdes $(71,05 \%)$; elle est suivie de la voie rectale $(16,37 \%)$.

Importance relative des plantes à
flavonoïdes

Plantes à flavonoüdes les plus utilisées et plantes associées

Une analyse des données révèle que, les plantes à flavonoïde les plus utilisées sont : Combretum micranthum (33 citations), Aloe vera (28), Ageratum conizoïdes (27), 
Cylicodiscus gabonensis (23), Eremomastax speciosa (23), Panax ginseng (21).

De nombreuses autres plantes à flavonoïdes entrent dans les recettes en association avec les plantes principales. Ces plantes sont: Afromomum meleguetta $K$. Schum., Aphrardisia sp., Camelia sinensis (Linn.) Kuntze, Capsicum annuum Linn., Citrus aurantifolia (Christm.) Swingle, Citrus maxima (Burm.) Merr., Elaeis guineensis Jacq., Musa sapientum Linn., Petroselinum sativum (Mill.) Nyman ex A. W. Hill., Tetrapleura tetraptera (Thonn.) Taub., Zingiber officinalis Roscoe. Citrus limon, déjà citée comme plante à flavonoïde principale, est la plante associée la plus sollicitée (14 citations).

\section{Indice de performance des plantes à flavonoüdes}

Les indices de performance (Ip) par maladie citée sont précisés entre parenthèses. Par exemple, Alchornea cordifolia $($ Ip $=3)$; Manihot esculenta (3) sont les espèces les plus performantes (très bonne performance) pour remédier aux problèmes d'anémie. Alafia multiflora $(I p=3)$ est l'espèce la plus performante pour le traitement du diabète. Tandis que, pour la même affection, Alstonia boonei (1), Cinchona pubescens (1), Combretum micranthum (1), Panax ginseng (1), Theobroma cacao (1), présentent une performance moyenne. Pausinystalia Johimbe $(I p=3)$ a une très bonne performance pour la faiblesse sexuelle. Pour les problèmes de cancer, Dacryodes edulis $(I p=3)$ a une très bonne performance, de même que Prunus Africana $(I p=3)$ pour le cancer de la prostate. Mangifera indica $(I p=3)$ et Irvingia gabonensis $(I p=3)$ présentent une très bonne performance face aux hémorroïdes. Stevia rebaudiana et Cleome ciliata ont une très bonne performance pour le traitement du mal de reins, alors que Solanum melongena (I $=$ 2) présente une bonne performance pour la même maladie. Annona muricata $(I p=2)$ a une bonne performance contre le mal de nerfs.

Pour le traitement de la typhoïde, la plupart des espèces prescrites présente une performance moyenne $(I p=1)$. Ce sont par exemple: Carica papaya, Cassia alata, Cinchona pubescens, Combretum micranthum, Eremomastax speciosa. Aucune espèce ne présente une bonne performance (Ip $\geq 2$ ) face à ces affections.

Pour le traitement du paludisme, aucune espèce n'a présenté une très bonne performance, mais Alstonia boonei $(I p=2)$, Bidens pilosa (2) et Chromolaena odorata (2) ont tout de même présenté une bonne performance.

Certaines espèces citées dans la liste ont des usages multiples autant dans un même groupe de maladies que pour des maladies de groupes différents. Carica papaya, Cassia alata, Cinchona pubescens, Combretum micranthum ont une performance moyenne pour la jaunisse et la typhoïde qui sont des maladies d'une même catégorie, ces espèces présentent également une performance moyenne contre le paludisme. Eremomastax speciosa a une bonne performance contre les érythèmes fessiers et une performance moyenne contre les dermatoses (maladies du même groupe) mais présente également une performance moyenne pour la jaunisse, la typhoïde et l'anémie. 


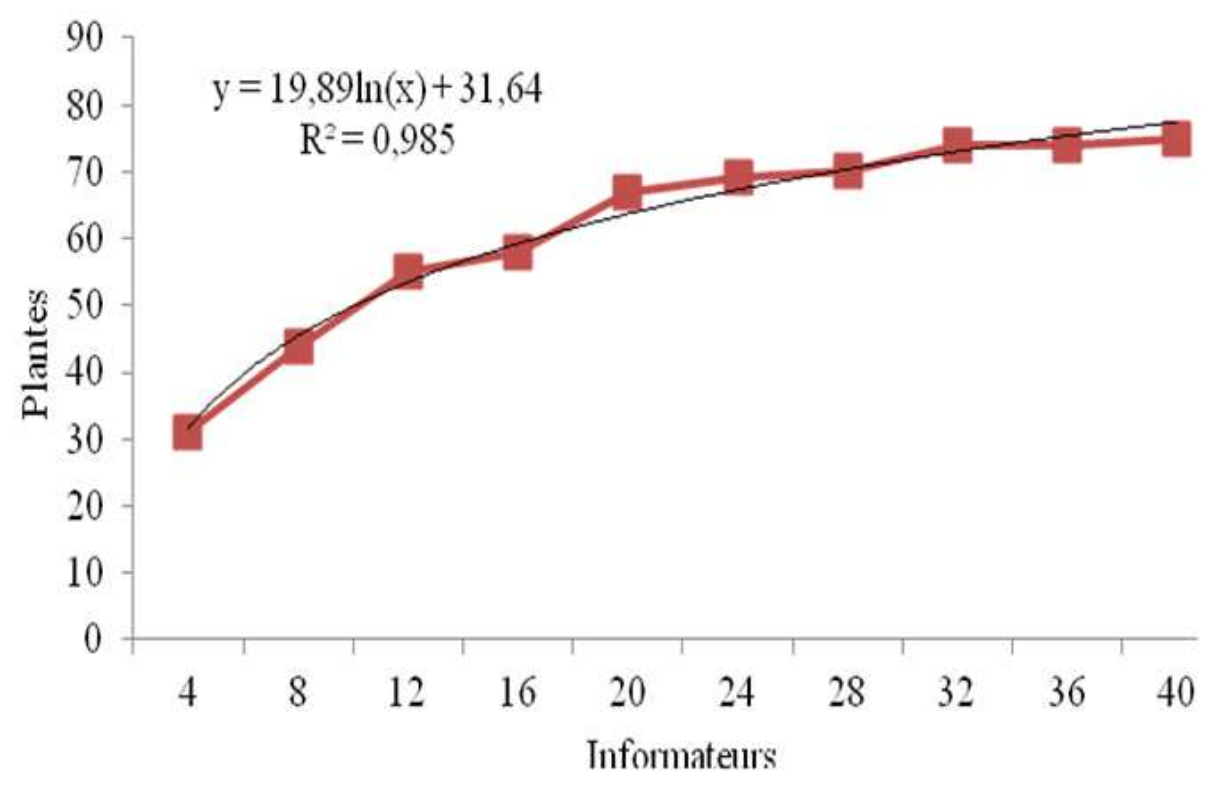

Figure 1: Courbe d'évolution du nombre de plantes à flavonoïdes en fonction du nombre d'informateurs.

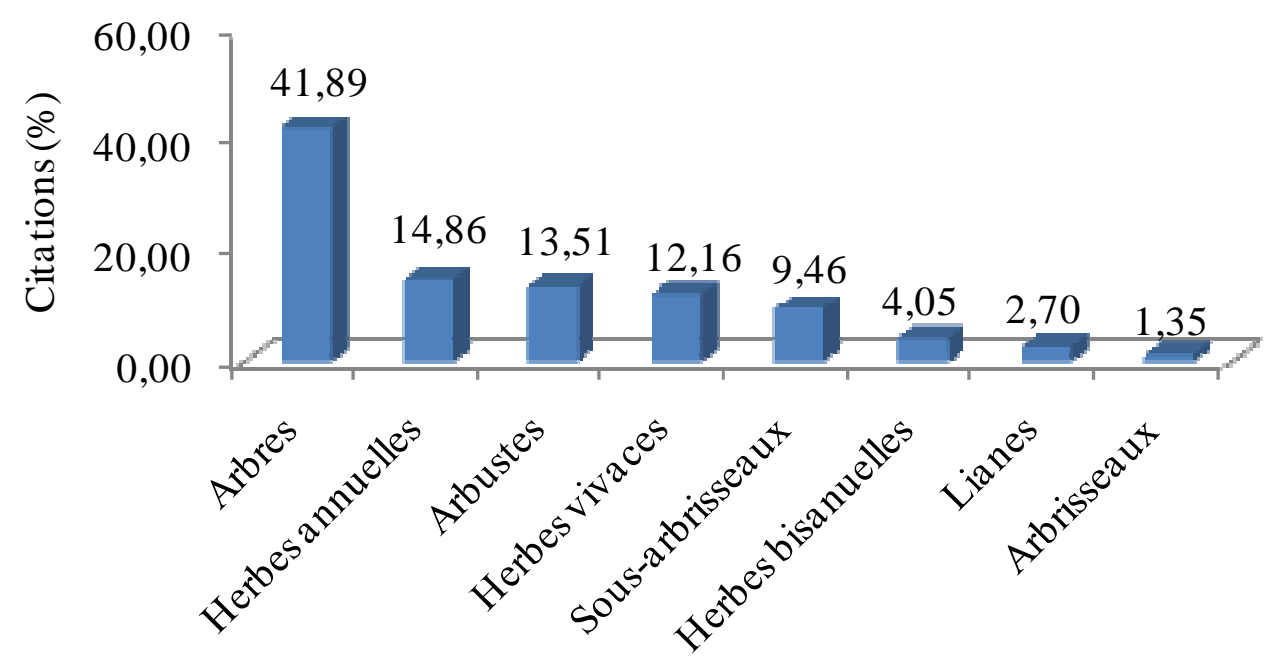

Types morphologiques

Figure 2 : Histogramme des types morphologiques. 


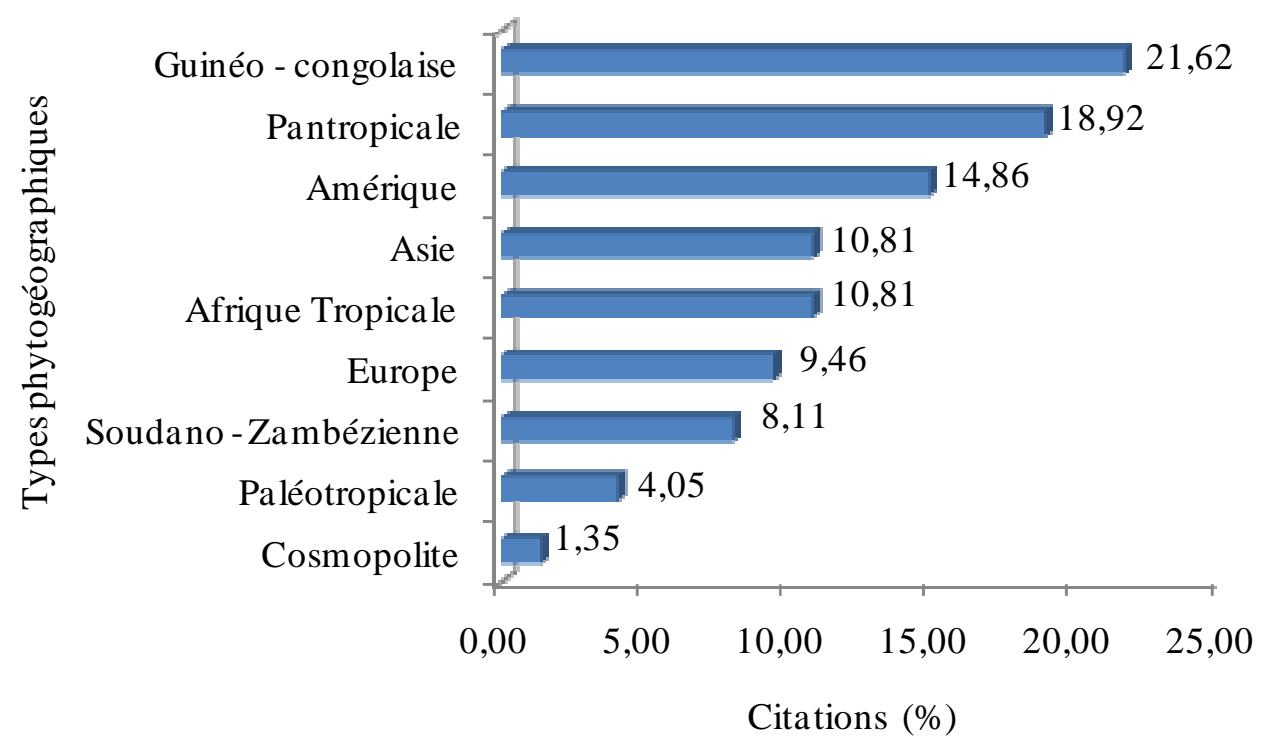

Figure 3 : Spectre pondéré (\% en citations) des types de distribution phytogéographiques.

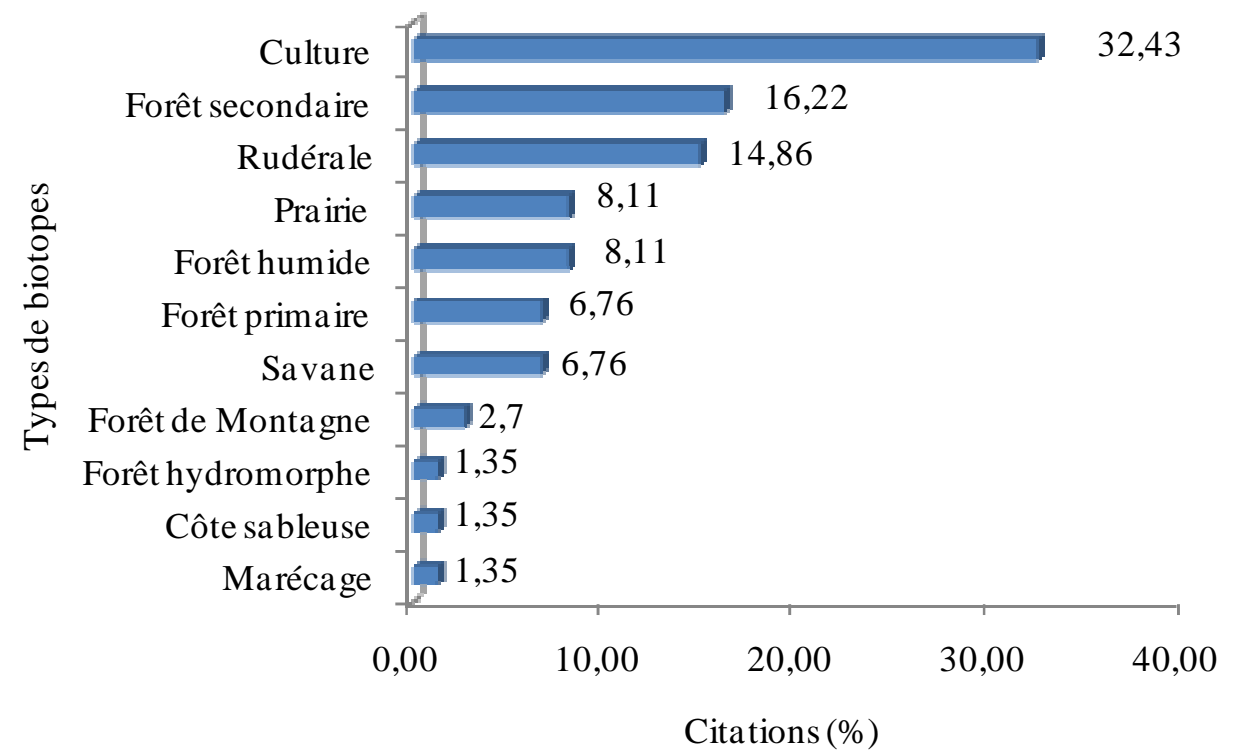

Figure 4 : Spectre pondéré (\% en citations) des types de biotope. 


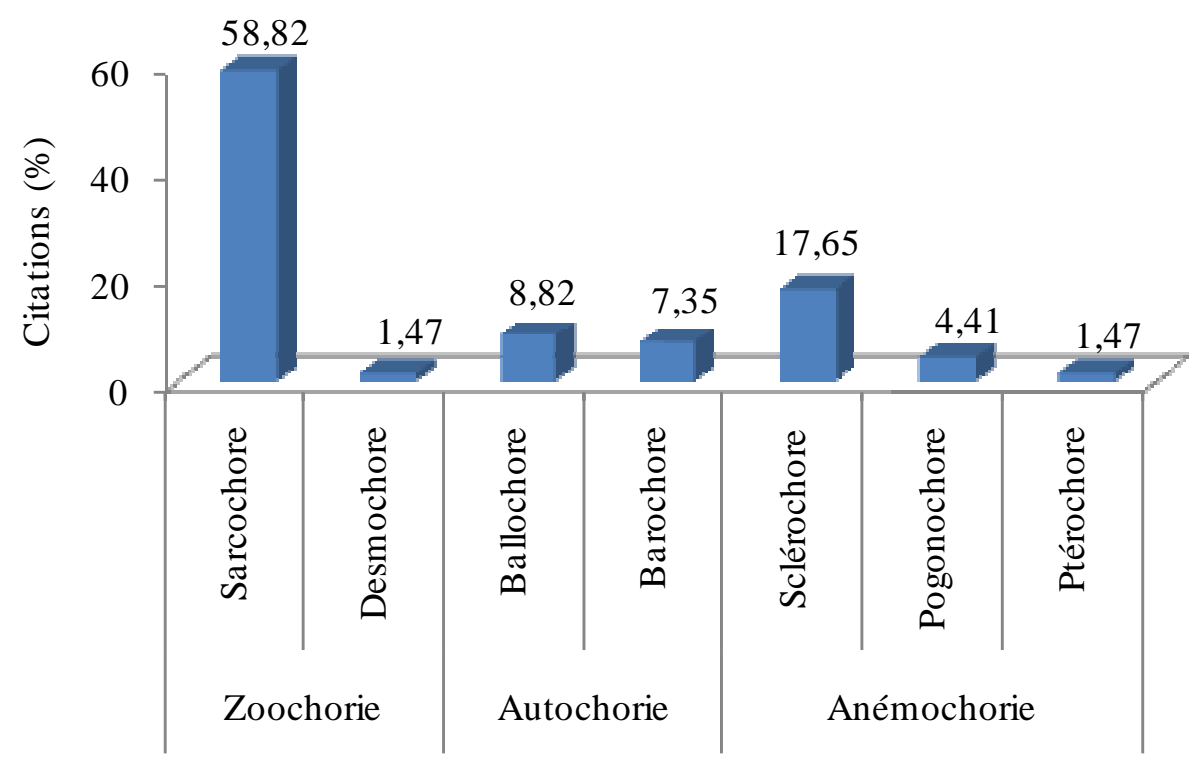

Types et modes de dissémination des diaspores

Figure 5 : Spectre pondéré ( $\%$ en citations) des types et modes de dissémination des diaspores.
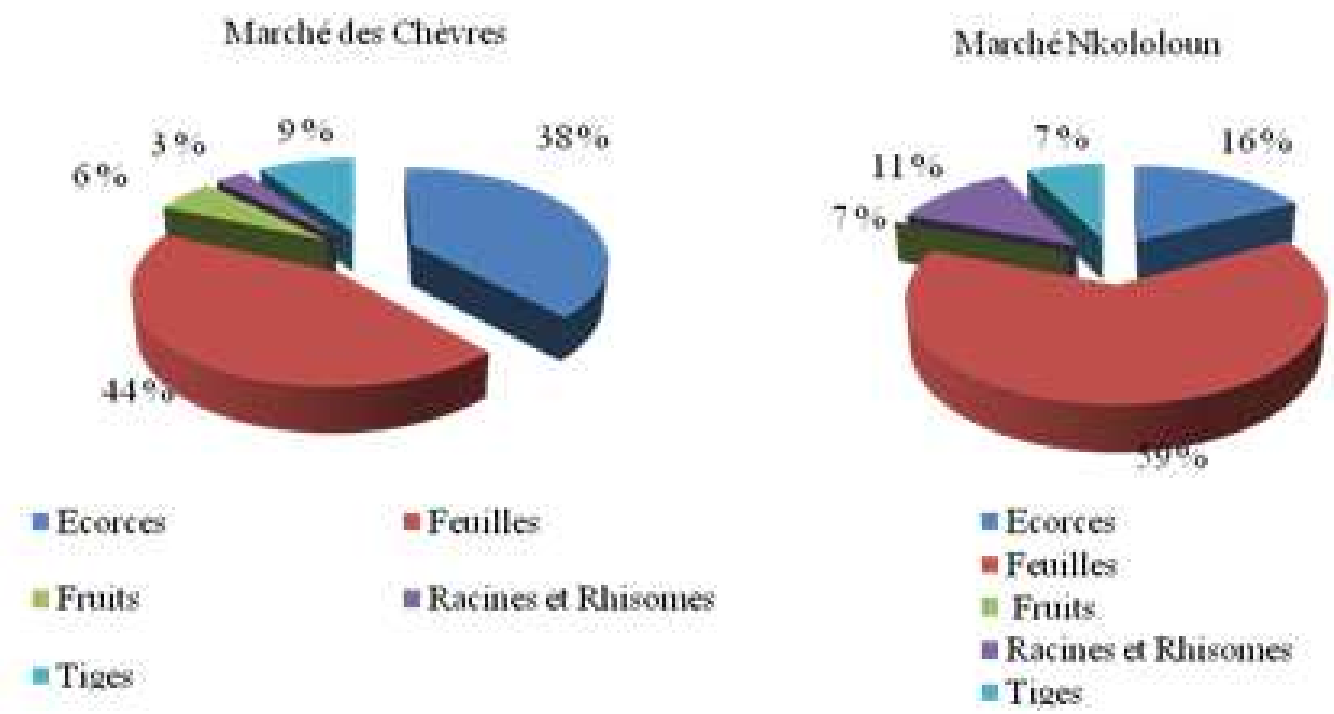

Figure 6 : Diagrammes des organes végétatifs des plantes à flavonoïdes dans les marchés. 


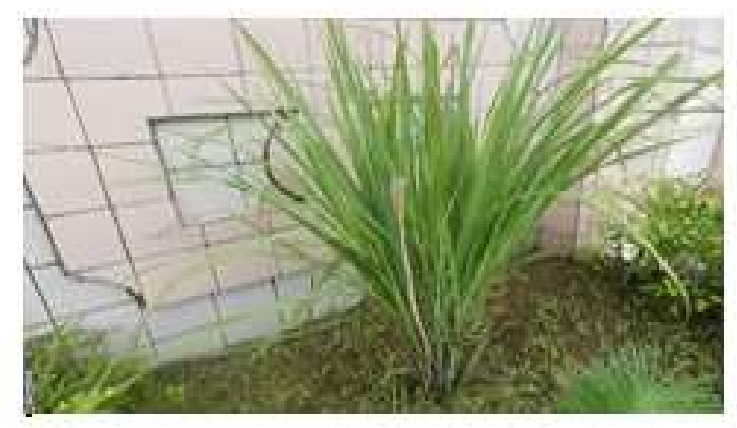

Pied de Cymbopogon citratus

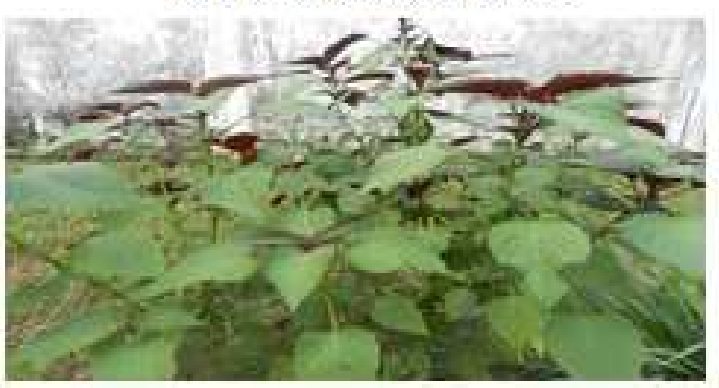

Pied de Evemomastax speciosa

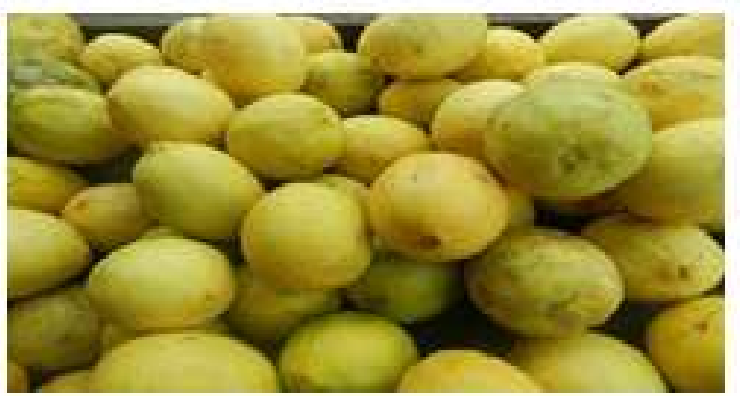

Fruits de Citrus limon

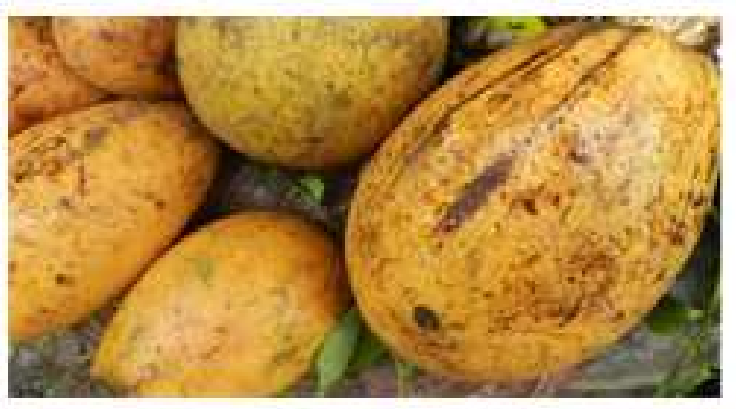

Fruits de Combretum micranthum

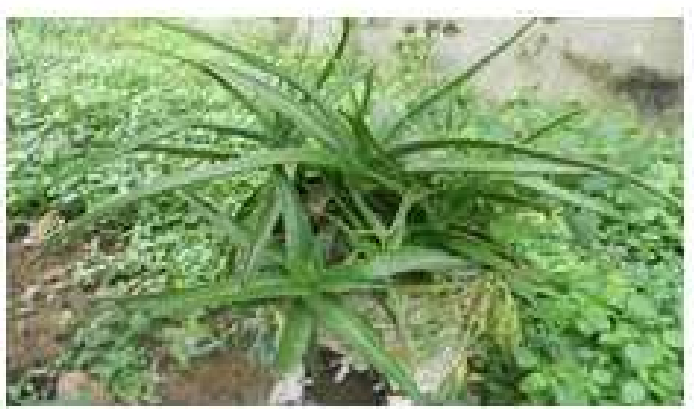

Pieds d'Aloe vera

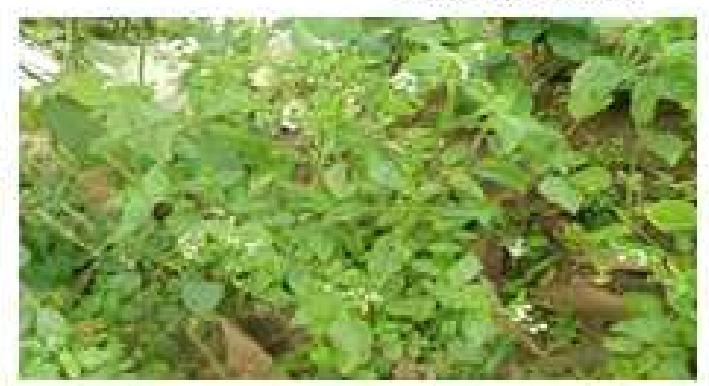

Feuilles et fleurs d'Ageratum conizoides

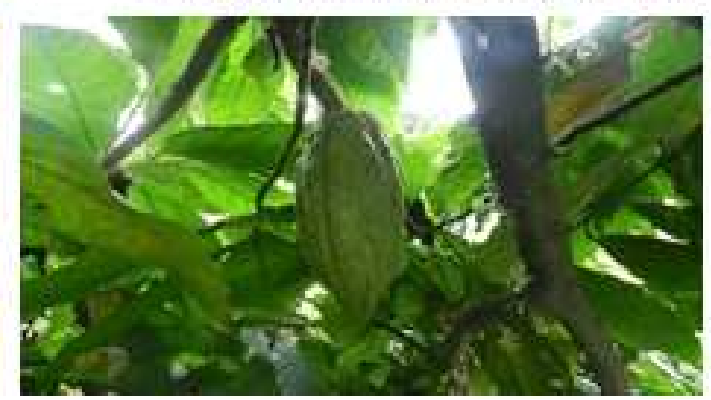

Feuilles et fruits de Theobroma cacao

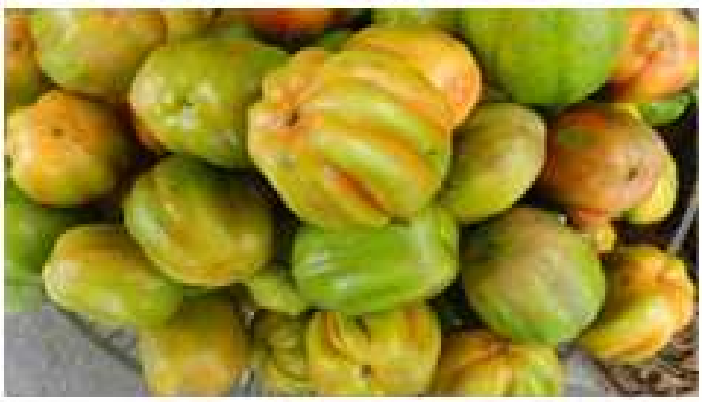

Fruits de Solanum melongena 


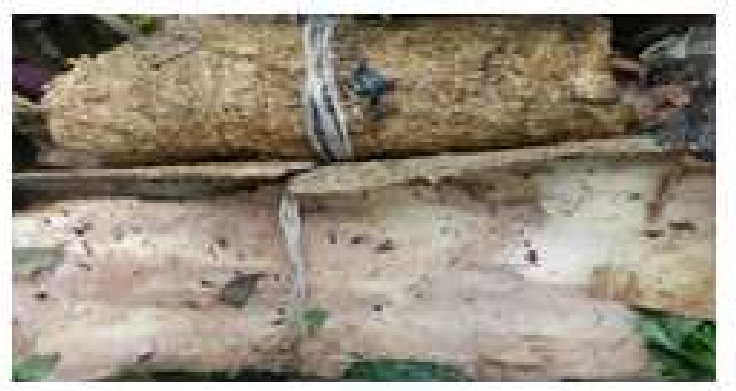

Ecorces de Cylicodiscus gabonensis

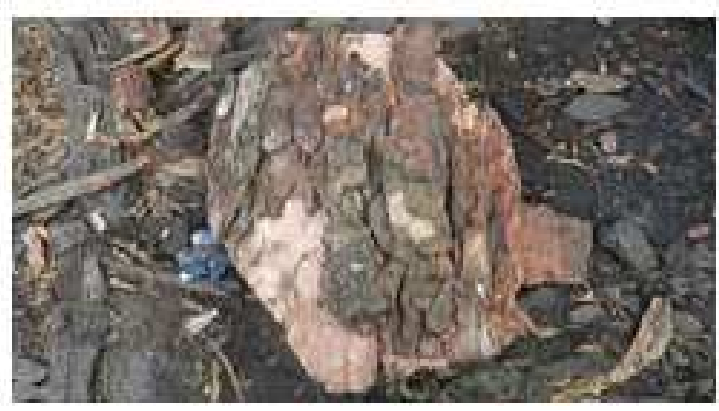

Ecorce d'Alstonia boonei

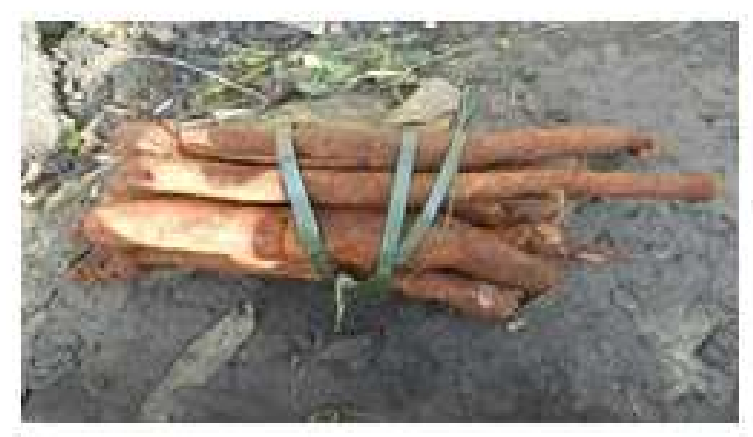

Racines de Panax ginseng

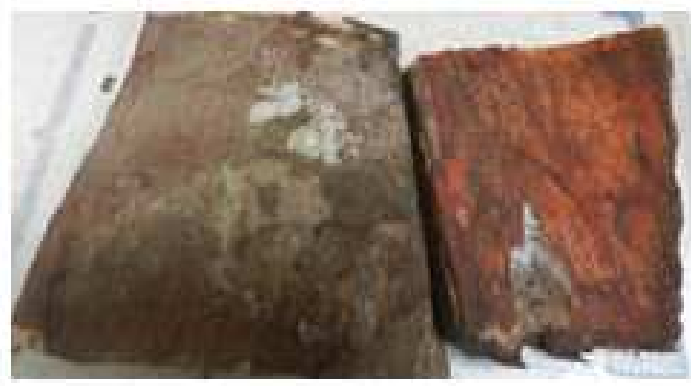

Ecorces d'Annona muricata

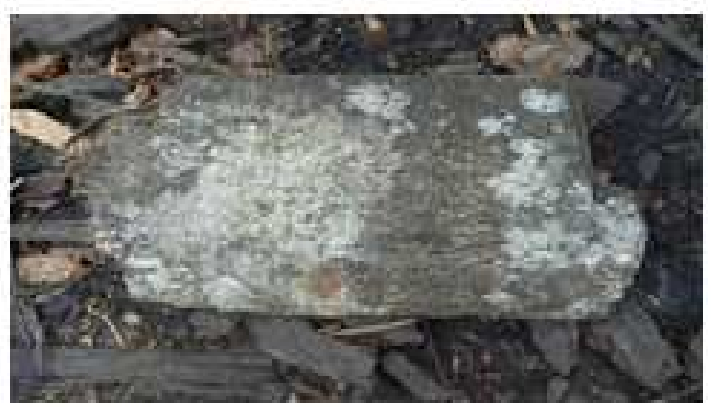

Ecorce de Pausinystalia Johimbe

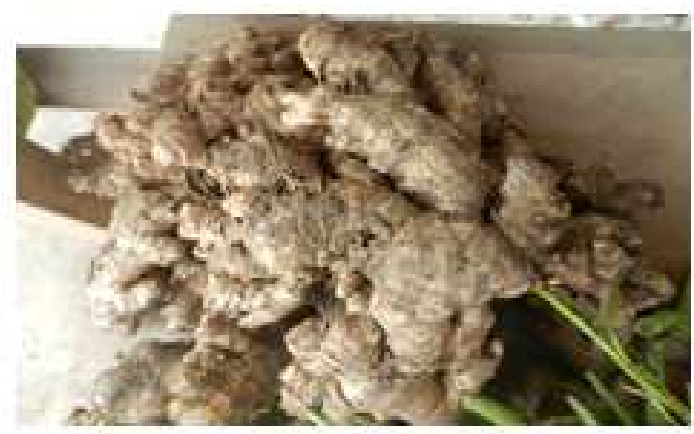

Rhizomes de Zingiber officinalis

Figure 7 : Photos illustrant les organes végétatifs de quelques plantes à flavonoïdes vendues dans les marchés de la ville de Douala. Photos prises par MVOGO OTTOU Patrice Brice. 


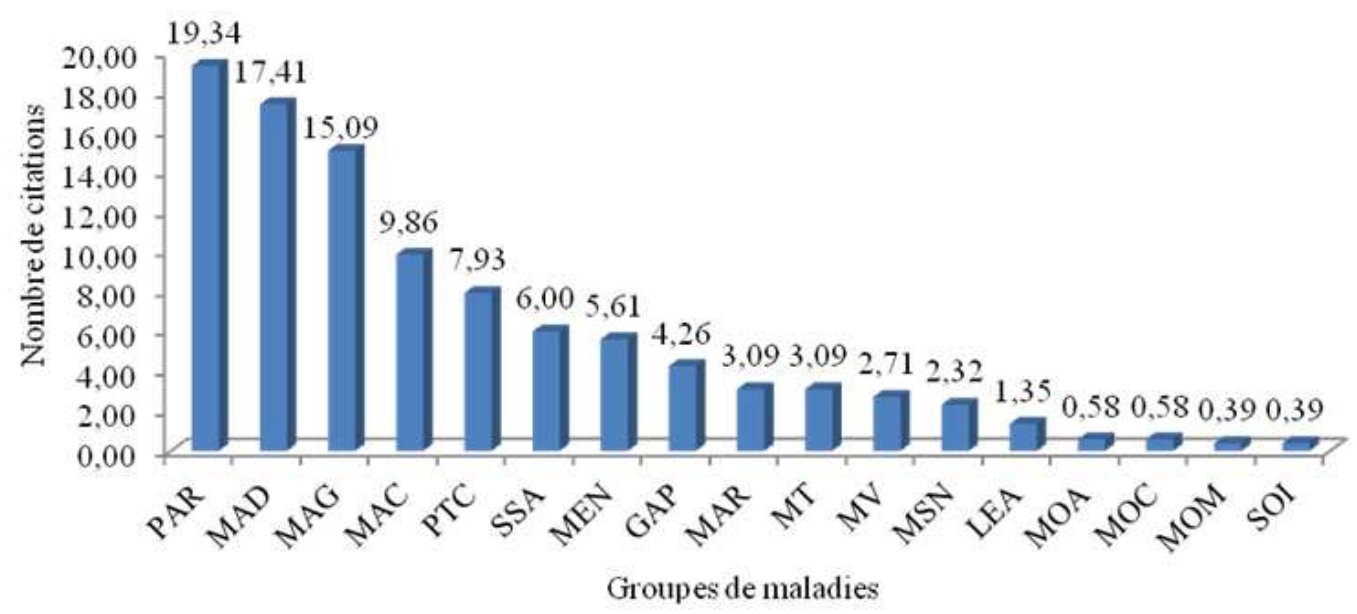

Figure 8 : Importance relative (en \% du nombre de citations) des groupes de maladies identifiés.

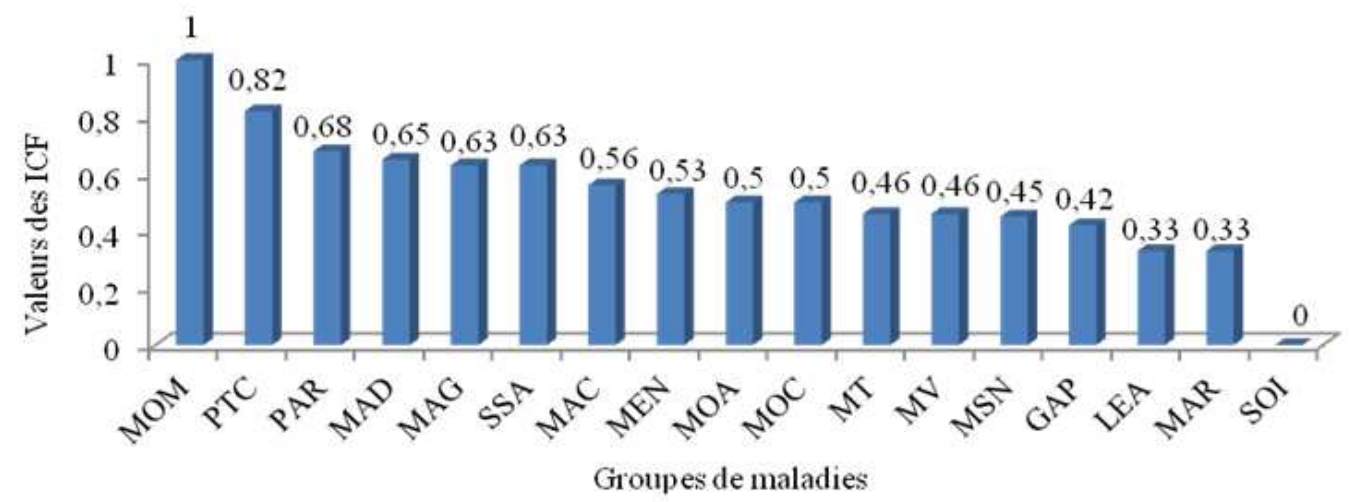

Figure 9 : Facteurs de consensus relevant les divergences de connaissances des vendeurs.

\section{DISCUSSION}

\section{Informations relatives aux enquêtés}

Les plantes médicinales sont vendues dans plusieurs marchés de la ville de Douala; certains étant plus fournis que d'autres. Dibong et al. (2011a) signalent que le marché des chèvres est le plus spécialisé dans la vente des plantes médicinales.

Les informateurs sont souvent très réservés et l'on note beaucoup de réticences notamment en ce qui concerne les plantes médicinales (Betti, 2001). Justifier dans ces conditions la représentativité de l'échantillon par le taux d'échantillonnage n'est pas indiqué
(Betti, 2002). C'est pourquoi la courbe de tendance indiquant l'évolution du nombre de plantes en fonction du nombre d'informateurs est le meilleur moyen d'apprécier l'importance des plantes à flavonoïdes citées par les informateurs. Le coefficient de corrélation le plus élevé $\left(R^{2}=0,985\right)$ est celui correspondant à la courbe logarithmique d'équation $\mathrm{Y}=$ $19,89 \ln (x)+31,64$. L'examen de cette courbe révèle qu'un ajout du nombre d'informateurs ne contribuerait pas à augmenter de manière significative la liste de plantes à flavonoïdes citées dans notre échantillon. Ainsi notre échantillon de plantes peut être considéré 
comme étant représentatif des plantes à flavonoïdes retrouvées dans les deux marchés.

L'engagement des hommes est remarquablement élevé dans les deux marchés. Ils fournissent en moyenne autant d'informations sur les plantes à flavonoïdes que les femmes. Ce résultat corrobore celui de Tchatat et Ndoye (2006) qui signalaient lors d'une étude des PFNLs en Afrique centrale qu'au Cameroun, la crise économique et par ailleurs le manque d'emploi en milieu urbain, amène les hommes à s'intéresser davantage à la commercialisation des plantes médicinales pour subvenir aux besoins de leur famille.

Les ressortissants de l'Ouest sont les plus nombreux dans les marchés de vente des plantes médicinales. Priso et al. (2011) trouvent des résultats similaires. Les ressortissants de l'Ouest constituent le groupe ethnique le plus important de la ville de Douala et ils sont l'un des groupes ethniques encore attachés à la tradition et aux valeurs culturelles des plantes.

Les vendeurs interrogés semblent avoir sensiblement le même âge (35 ans), ils appartiennent à la classe des adultes. Ils ont une plus grande expérience dans la pratique de la pharmacopée à base des plantes par rapport aux jeunes et parviennent à reconnaître la plupart des espèces végétales par simple contact visuel (Tchatat et Ndoye, 2006). En effet, les jeunes beaucoup plus préoccupés par les études, le sport et autres formes de loisirs, s'intéressent très peu à la connaissance des plantes médicinales. Ils rompent ainsi tout contact avec les plantes médicinales et réduisent le flux de connaissances entre les vieux et eux. Une telle situation pourrait entraîner un risque de perte de connaissances sur l'utilisation des plantes médicinales en milieu urbain.

\section{Caractéristiques floristiques des plantes à flavonoïdes}

La connaissance des ressources est une condition indispensable pour leur mise en valeur et leur bonne gestion. En effet, connaître les caractéristiques floristiques des plantes à flavonoïdes permettrait d'optimiser leur bonne gestion. L'histogramme des types biologiques observé concorde avec celui trouvé au par Dibong et al. (2011a) qui ont recensé $60 \%$ de ligneux contre $40 \%$ d'herbacées. Adomou et al. (2012) trouvent des résultats similaires dans une étude ethnobotanique des plantes médicinales vendues dans le marché d'Abomey-Calavi au Bénin. Les espèces ligneuses sont sollicitées la plupart du temps pour leur écorce ou leurs racines et l'exploitation de ces organes peut s'avérer préjudiciable pour la plante et même pour son écosystème. Makumbelo et al. (2008) considèrent que les arbres sont les types morphologiques les plus vulnérables. En effet, outre la quantité du produit à exploiter, la gravité de cette vulnérabilité varie en règle générale, en fonction de la technique de prélèvement. Par ailleurs, la strate herbacée est constituée des espèces de petite taille, présentant une maturité précoce, une descendance nombreuse et une capacité de régénération très rapide leur permettant d'être tout le temps disponible, réduisant ainsi la pression sur les écosystèmes (Dibong et al., 2011b).

Les espèces Guinéo-congolaises sont nombreuse (22\%). Betti (2001) trouve des résultats similaires. Il montre pour la ville de Bertoua et de Yaoundé, une faible proportion des espèces étrangères $(23,76 \%)$ mais plutôt une importante domination des espèces du domaine guinéen $(67,54 \%)$. Cette dominance d'espèces Guinéo-congolaises traduit ainsi le faible impact des cultures étrangères sur l'exploitation des plantes médicinales et la 
conservation des cultures locales. Toutefois, l'utilisation des plantes médicinales venues d'ailleurs (11 d'Amérique, 8 d'Asie et 7 d'Europe) entraîne progressivement l'altération de la flore locale et une perte de l'identité culturelle (Bangirinama et al., 2008).

Parmi les plantes à flavonoïdes rencontrées dans les marchés de la ville de Douala, les espèces forestières prédominent (35\%). Dibong et al. (2011a) signalaient également une domination des espèces ligneuses de forêts. Cette importance des espèces forestières s'explique par l'appartenance de la ville à la zone de forêt dense sempervirente littorale et biafréenne. La présence des espèces cultivées $(33 \%)$ est aussi significative. Ces espèces se retrouvent domestiquées dans des agro-écosystèmes. En effet, la domestication des plantes à flavonoïdes peut s'avérer être une alternative dans les stratégies d'exploitation durable de cette ressource.

Les espèces sarcochores sont les plus représentées $(60 \%)$ et la zoochorie est le mode de dissémination qui prédomine $(70 \%)$. Ces résultats corroborent ceux obtenus dans le Dja sur les plantes médicinales qui montrent l'importance des espèces zoochores en zone forestière (Betti, 2001).

Importance relative des organes utilisés, des maladies soignées et des plantes à flavonoïdes

\section{Organes utilisés}

La pharmacopée dans les marchés de la ville de Douala est assez riche et diversifiée. Une analyse des données révèle que $76 \%$ des plantes citées par les vendeurs sont des plantes à flavonoïdes. L'importance des feuilles parmi les parties aériennes des organes végétatifs collectés dans les deux marchés peut être attribuée non seulement à leur facilité de prélèvement, mais aussi à leur abondance et leur disponibilité. En effet, Douala est situé en zone de forêt sempervirente littorale et les feuilles des arbres, toujours vertes, sont disponibles tout au long de l'année (Priso et al., 2011). Selon Ouattara (2006), le prélèvement de $50 \%$ des feuilles d'un arbre n'affecte pas de façon significative sa survie. Par ailleurs, l'intérêt porté aux écorces relève de leur richesse en métabolites secondaires responsables des propriétés biologiques de la plante (Yinyang et al., 2014).

\section{Maladies soignées}

Le groupe de maladies le plus représenté est celui des maladies infectieuses et parasitaires $(19,34 \%)$ suivi du groupe des maladies de l'appareil digestif $(17,41 \%)$. Ces résultats s'accordent avec ceux de Betti (2002). De même, Zerbo et al. (2007), dans leurs travaux réalisés parmi les Sanan (NordOuest du Burkina Faso), observent une prédominance des troubles digestifs $(29 \%)$ et des infections et infestations $(22 \%)$. Le nombre de recettes contre le paludisme d'une part et contre la typhoïde d'autre part serait la cause du pourcentage élevé de ces groupes de maladies. En effet, le Cameroun est situé dans la zone $\mathrm{C}$ (zone à fort risque de paludisme). Ouattara (2006) indique que le paludisme représente $17,78 \%$ des maladies traitées par les plantes médicinales en Côte d'Ivoire. Il souligne que cette affection constitue la première cause des consultations générales en Afrique tropicale. Par ailleurs, la typhoïde représente aussi une affection importante. L'installation et la prolifération de cette maladie pourraient être favorisées par des facteurs tels que la mauvaise qualité des eaux consommables, leur mauvaise politique d'assainissement, les conditions précaires dans lesquelles vivent les populations de la ville et les habitudes alimentaires de celles-ci. 
Plantes à flavonoüdes et performance pour les maladies

Les flavonoïdes rassemblent une très large gamme de composés polyphénoliques formés par un squelette de base à 15 atomes de carbones ayant une structure commune en C6-C3-C6 de type phényl-2-benzopyrane (Kooter et al., 2002; Marfak, 2003). Leur fonction principale chez les plantes est attribuée aux colorations qu'ils sont à même d'induire chez celles-ci (Marfak, 2003). L'absorption des flavonoïdes dans l'ultraviolet produit des motifs perceptibles par les insectes et capables de les guider vers le nectar (Bruneton, 2009). Ils interviennent aussi dans la défense des plantes contre les herbivores. Certains flavonoïdes produits par la plante activent les gènes bactériens responsables du processus de nodulation dans la symbiose entre les Fabacées et les bactéries du genre Rhizobium (Kistner et Parniske, 2002).

Les flavonoïdes sont de puissants antioxydants car permettent le piégeage direct des EOR (Espèces oxygénées réactives), l'inhibition des enzymes et la chélation des traces métalliques responsables de la production de EOR. Ce sont de puissants antiradicalaires. Ils inhibent l'oxydation du cholestérol LDL par les radicaux libres, abolissent la tendance des cellules sanguines de petite taille ou plaquettes à se regrouper et à former des caillots sanguins. Leur intérêt contre l'obésité a été relevé (Morikawa et al., 2008). Les flavonoïdes contribuent significativement à la digestion, réduisent les risques cardiovasculaires du fait qu'ils agissent comme des poubelles à radicaux libres en prévenant et en arrangeant les dommages causés par les EOR (Mpondo et al., 2012). Chen et al. (2008) notent le rôle joué par ces molécules dans la protection des neurones. Ulanowska et al. (2006) évoquent leurs intérêts remarquables contre les affections microbiennes.

Les plantes telles que Combretum micranthum (Ip = 1), Aloe vera (1), Alstonia boonei (2), Carica papaya (1), Cinchona pubescens (1) bien que n'ayant pas une performance maximale, sont régulièrement prescrites par les vendeurs pour le traitement du paludisme. Betti et al. (2013) signalent que ces plantes sont utilisées pour le traitement de la même maladie dans de nombreux pays africains notamment le Cameroun. Ces auteurs révèlent une activité importante de ces plantes contre Plasmodium falciparum. Toutefois, les études sur l'implication des flavonoïdes dans la lutte antipaludéenne sont limitées (Mpondo et al., 2012). Il semble tout de même que la présence des flavonoïdes (flavanone et chalcones) dans les extraits de ces plantes ait une activité antiplasmodiale par inhibition des enzymes parasitaires vitales telles que la cystéine protéase (Makam, 2003; Portet, 2007).

Combretum micranthum en plus d'être un puissant antipaludéen, est régulièrement sollicité dans le traitement de la typhoïde (Ip = 1), de la jaunisse (1) et du diabète (1). La vitexine (C-glycosyl-8 apigénine), l'isovitexine (C-glycosyl-6 apigénine), l'orientine (C-glycosyl-8 lutéoline), l'homoorientine (C-glycosyl-6 lutéoline) sont les flavonoïdes présents dans Combretum micranthum (Chika et Bello, 2010; Welch, 2010). L'effet synergique de ces flavonoïdes pourrait être responsable de l'activité antioxydante permettant de limiter la peroxydation liée au diabète. De plus, il aiderait à maintenir une pression artérielle et une fonction rénale normales, en évitant les effets toxiques de l'hyperglycémie, en particulier, la glycation sur les vaisseaux sanguins et les reins. Par ailleurs, les vendeurs signalent que Combretum micranthum est un 
puissant désinfectant et que, ses vertus favorisent l'excrétion urinaire et la sécrétion biliaire. Anonyme (2011) signalait que Combretum micranthum est un puissant dépuratif et diurétique qui agit efficacement contre les troubles digestifs et est préconisée dans le traitement du péristaltisme intestinal.

L'analyse des résultats montre que Panax ginseng présente un indice de performance $1(I p=1)$ pour le diabète et la purification du sang, Cymbopogon citratus un indice de performance $1(I p=1)$ pour les MCV. Annona muricata quant à lui présente un indice de performance $1(I p=1)$ pour l'hypertension artérielle, les MCV et la purification $\mathrm{du}$ sang. Alafia multiflora présente un indice de performance $3(I p=3)$ pour le diabète et Theobroma cacaoun indice de performance $1(I p=1)$ pour le diabète et l'hypertension artérielle. En effet, les flavonoïdes présents dans Theobroma cacao (catéchine, épicatéchine et quercétine), ceux présents dans Panax ginseng (kaempférol, trifoléine, lutéoléine, quercétine), dans Cymbopogon citratus (flavones et flavonols), Annona muricata (lutéoléine, quercetine, catéchine et épicatéchine) et dans Alafia multiflora sont capables de piéger les radicaux libres et d'activer les autres antioxydants présents dans le corps (Qian et Nihorimbere, 2004; Vita, 2005; Chandana Venkateswara et Vijayakuma, 2008; Eriksson, 2009; Nawwar et al., 2012). Par ailleurs, ces flavonoïdes préviennent l'oxydation des lipoprotéines de faible densité (LDL), de même que l'agrégation des plaquettes sanguines (Teissedre, 2005), évitant ainsi l'athérosclérose, un processus menant à l'apparition des maladies cardiovasculaires. En outre, ils améliorent l'élasticité de la paroi des vaisseaux sanguins contribuant ainsi à la bonne fluidité du sang (Vita, 2005).
Panax ginseng est également la plante la plus prescrite par les vendeurs contre le mal de reins $(I p=1)$ et Annona muricata, la plus prescrite contre le mal de nerfs $(I p=2)$. En effet, les flavonoïdes de Panax ginseng semblent diminuer non seulement le développement des complications diabétiques, telles que la néphropathie (atteinte des reins) et la rétinopathie (atteinte de la rétine) mais ont aussi un effet diurétique sur les corpuscules de Malpighi (Cho et al., 2014). Par ailleurs, les travaux de Chen et al. (2008) révèlent que, la lutéoléine, flavonoïde présente dans Annona muricata inhibe le captage de la dopamine par les neurones. Les flavonoïdes présents dans ces plantes inhibent la production excessive du TNF- $\alpha$, du NO et du superoxyde dans les cultures de neurones mésencéphaliques; protégeant ceux-ci contre de nombreux dommages notamment des inflammations (Cho et al., 2014).

Ageratum conyzoïdes s'avère être un puissant antibiotique et anti-inflammatoire car cette plante est régulièrement citée dans le traitement des infections $(I p=1)$ et des ulcères gastriques $(I p=1)$. Les flavonoïdes de Ageratum conyzoïdes que sont ageconyflavone $\mathrm{A}, \mathrm{B}$ et $\mathrm{C}, \quad 5^{\prime}$ methoxynobiletine, linderoflavone B, eupalestine, nobiletine quercetine, sinensetine, kaempférol seraient responsables des propriétés analgésiques, anti-inflammatoires, antientéralgiques, antipyrétiques et antispasmodiques (Kamboj et Saluja, 2008). En effet, l'action pharmacologique de ces flavonoïdes suggère qu'ils pourraient présenter un intérêt dans le traitement des désordres allergiques en sous-régulant les mastocytes et en inhibant la sécrétion de l'histamine et la hausse du taux de calcium intracellulaire (Akroum, 2011).

Le citron (Citrus limon) est la plante à flavonoïdes la plus utilisées comme plante 
associées dans les recettes médicamenteuses. L'ériocitrine et l'hespérétine, deux flavonoïdes contenus dans le citron, sont capables de neutraliser les radicaux libres du corps et, ainsi, prévenir l'apparition des maladies cardiovasculaires, de certains cancers et d'autres maladies chroniques (Minato et Miyake, 2003). En outre, les associations des plantes avec d'autres se font dans le but d'augmenter le pouvoir du principe actif. Il s'agit d'une synergie thérapeutique car ces associations de plantes permettent non seulement de renforcer l'action thérapeutique des composantes principales des recettes, mais aussi de traiter les symptômes secondaires de la maladie (Joy et al., 2001). De même, une plante peut être utilisée en association avec une autre pour diminuer le caractère irritant ou toxique du principe actif de la plante principale. Dibong et al. (2011a) montrent que le jus de citron associé à des recettes indiquées contre la typhoïde ou la jaunisse a pour rôle de redonner du tonus au patient affaibli par la maladie.

La performance moyenne de certaines plantes pour certaines maladies viendrait du fait que ces plantes soient sollicitées dans le traitement de nombreuses autres maladies. En effet, les vendeurs n'ont pas la parfaite maîtrise des symptômes des maladies dont ils prescrivent les traitements. Ils assimilent par exemple les symptômes du paludisme à ceux de la typhoïde et de la jaunisse. En outre, ils prescrivent souvent les mêmes plantes pour les maladies d'un même groupe.

Les valeurs des ICFs sont maximales. Canales et al. 2005 trouvent des résultats similaires. Les plantes prescrites pour les mêmes groupes de maladies font l'unanimité dans les marchés renforçant ainsi les performances des plantes pour les maladies. En effet les marchés étant des espaces où les vendeurs sont à proximité les uns des autres, permet aux vendeurs de se côtoyer et d'échanger les connaissances les uns avec les autres. En outre, ces vendeurs sont issus d'une même région et ont par conséquent les connaissances presque identiques sur l'utilisation des plantes médicinales.

$\mathrm{La}$ voie orale est la voie d'administration dans $79 \%$ des traitements. De ce fait, la gestion et l'exploitation durable des plantes à flavonoïdes nécessitent la connaissance précise des doses prescrites et des modes de conservations. En effet, Malgré les effets bénéfiques des flavonoïdes, plusieurs études indiquent un effet mutagène et génotoxique dans certains systèmes expérimentaux bactériens ou mammifères, effets liés à une activité pro-oxydante. De nombreuses études montrent à l'évidence que les activités biologiques des flavonoïdes sont doubles. Ils peuvent agir en tant qu'antimutagène/promutagène, antioxydant/ pro-oxydant. Tout dépend largement des quantités consommées et des conditions physiologiques de l'organisme. Un surdosage peut entraîner des dommages allant jusqu'à des modifications de l'ADN (Skiloba et Smith, 2000).

\section{Conclusion}

Il ressort de cette étude que les marchés des plantes médicinales regorgent d'un énorme potentiel de plantes à flavonoïdes dont la plupart appartiennent à notre environnement immédiat et dont les feuilles et les écorces sont les organes végétatifs les plus utilisées. Ces plantes à flavonoïdes $\mathrm{du}$ fait de leurs multiples propriétés, sont des solutions face aux maladies cardiovasculaires, au diabète, aux cancers, aux maladies vénériennes et aux maladies microbiennes. Par ailleurs, l'exploitation des plantes à flavonoïdes est 
une activité régulière et permanente qui génère des emplois mais nécessite une parfaite connaissance des modes d'emploi pour le bien être des vendeurs et des consommateurs. Les différentes propriétés citées peuvent justifier l'intégration de ces produits forestiers non ligneux dans les programmes d'aménagement forestier, en vue de leur exploitation soutenue et durable. Une telle exploitation passe par la maîtrise des caractéristiques floristiques et l'évaluation du potentiel de ces PFNLs. Par ailleurs, les connaissances précises sur les doses prescrites et les techniques de conservation s'avèrent être nécessaire.

\section{REFERENCES}

Abdou Bouba A. 2009. Contribution à l'étude $\mathrm{du}$ développement d'un aliment fonctionnel à base d'épices du Cameroun: Caractérisation physicochimique et fonctionnelle. Thèse de Doctorat, Université de Ngaoundéré, Cameroun. 193p.

Adjanohoun E, Cusset G, Issa LO, Keita A, Lebras M, Lejoly J, Waechter P. 1989. Banque de données de médecine traditionnelle et de pharmacopée (pharmel). Notice pour la récolte et l'entrée des données, ACCT, Paris.

Adjanohoun E, Cusset G, Issa LO, Keita A, Lebras M, Lejoly J. 1994. Banque de données de médecine traditionnelle et de pharmacopée (Pharmel). Notice pour la collecte et l'entrée des données, seconde édition. A.C.C.T. Paris.

Adjanohoun E. 2000. La biodiversité face au développement des industries pharmaceutiques africaines. In Réseau des « espèces ligneuses médicinales », Eyog Matig O, Adjanohoun E, de Souza $\mathrm{S}$ et Sinsin B (eds). Compte rendu de la première réunion du réseau tenue 15-17 décembre 1999 à la station IITA Cotonou, Bénin, 88-103.

Adomou AC, Yedomonhan H, Djossa B, Legba SI, Oumorou M, Akoegninou A. 2012. Etude Ethnobotanique des plantes médicinales vendues dans le marché d'Abomey-Calavi au Bénin. Int. J. Biol. Chem. Sci., 6: 745-772.

Akroum S. 2011. Etude Analytique et Biologique des Flavonoïdes Naturels. Thèse de Doctorat, Université Mentouri de Constantine, Algérie. 113p.Anonyme. 2011. Combretum micranthum; propriétés, bienfaits et précautions d'utilisation. http://www. les-plantesmedicinales.net [11 03 2011].

Aubréville A. 1962. Position chorologique du Gabon. Flore du Gabon, 2: 3-11.

Awono A, Manirakiza D, Ingram V. 2009. Mobilisation et renforcement des capacités des petites et moyennes entreprises impliquées dans la filière des produits forestiers non ligneux en Afrique Centrale. CIFOR : Cameroun. http: camerounforet.com/fr/bibliotheque/ 10666.

Bangirinama F, Bigendago MJ, Havyarimana F, Bogaert J. 2011. Analyse de la flore des jachères du Burundi. Bull. Sci. Inst. Natl. Environ. Conserv. Nat., 10: 1-19.

Betti JL. 2001. Usages traditionnels et vulnérabilité des plantes médicinales dans la réserve de biosphère du Dja et dans les marchés de Yaoundé, Cameroun. Thèse Doctorat, Université Libre de Bruxelles, Belgique, 289p.

Betti JL. 2002. Medicinal plants sold in Yaoundé markets, Cameroon. African Study Monographs, 23: 47-64.

Betti JL, Iponga DM, Yongo OD, Mbomio DO, Yobo CM, Ngoy A. 2013. Ethnobotanical study of medicinal plants of the Ipassa-Makokou Biosphere Reserve, Gabon: Plants used for treating 
malaria. Journal of Medicinal Plants Research, 7: 2300-2318.

Biyiti LF, Meko'o DJL, Tamzc V, Amvam Zollo PH. 2004. Recherche de l'activité antibactérienne de quatre plantes médicinales camerounaises. Pharm. Med. Trad. Afr., 13: 11-20.

Bruneton J. 2009. Pharmacognosie, Phytochimie et Plantes Médicinales ( $4^{\mathrm{e}}$ édn, revue et augmentée). Tec \& Doc, Éditions Médicales Internationales : Paris ; 1288.

Canales M, Hern’andez T, Caballero J, Romo de Vivar A, Avila G, Duran A, Lira R. 2005. Informant consensus factor and antibacterial activity of the medicinal plants used by the people of San Rafael Coxcatl'an, Puebla, M'exico. Journal of Ethnopharmacology, 97: 429-439.

Chandana Venkateswara R, Vijayakumar M. 2008. Effect of quercetin, flavonoids and $\alpha$ - tocopherol, an antioxidant vitamin on experimental reflux oesophagitis in rats. Eur. J. Pharmacol., 589: 233-238.

Chen HQ, Jin ZY, Wang XJ, Xu XM, Deng L, Zhao JW. 2008. Luteolin protects dopaminergic neurons from inflammation-induced injury through inhibition of microglial activation. Neurosci. Lett., 448: 175-179.

Chika A, Bello SO. 2010. Antihyperglycemic activity of aqueous leaf extract of Combretum micranthum (Combretaceae) in normal and alloxan-induced diabetic rats. J. Ethnopharmacol., 129: 34-37.

Cho K, Song SB, Tung NH, Kim KN, Kim YH. 2014. Inhibition of TNF-a-Mediated NF-kB Transcriptional Activity by Dammarane-Type Ginsenosides from Steamed Flower Buds of Panax ginseng in HepG2 and SK-Hep1 Cells. Biomol. Ther., 22: 55-61.
Dibong SD, Mpondo Mpondo E, Ngoye A, Kwin NF, Betti JL. 2011a. Ethnobotanique et phytomédecine des plantes médicinales vendues sur les marchés de Douala, Cameroun. Journal of Applied Biosciences, 37: 2496-2507.

Din N, Senger P, Priso JR, Dibong SD, Amougou A. 2008. Logging activities in mangrove forests. A case study of Douala Cameroon. Africa Journal in Environmental Science and Technology, 2: 22-30.

Din N, Mpondo E, Dibong SD, Kwin NF, Ngoye A. 2011. Inventory and identification of plants used in the treatment of diabetes in Douala town (Cameroon). European Journal of Medicinal Plant, 1: 60-73.

Eriksson TL. 2009. Effects of Panax ginseng, ginsenosides and quercetin. Linköping Studies in Health Sciences, 103: 1-61.

Joy PP, Thomas J, Mathew S, Skaria BP. 2001. Medicinal plants. Tropical Horticulture, 2: 449-632.

Heinrich M, Ankli A, Frei B, Weimann C, Sticher O. 1998. Medicinal Plants in Mexico, Healer's Consensus and Cultural Importance. Social Science and Medicine, 47: 1859-1871.

Kamboj A, Saluja AK. 2008. Ageratum conyzoides L.: A review on its phytochemical and pharmacological profile. Int. J. Green. Pharm., 2: 59-68.

Kistner C, Parniske M. 2002. Evolution of signal transduction in intracellular symbiosis. Trends Plant Sci., 7: 511-518.

Koné D. 2009. Enquête ethnobotanique de six plantes médicinales maliennes extraction, identification d'alcaloïdes caractérisation, quantification de polyphénols : etude de leur activité antioxydante. Thèse de Doctorat Université de Bamako, Mali, 157p. 
Kooter IM, Steiner RA, Dijkstra BW, van Noort PI, Egmond MR, Huber MEPR. 2002. Caracterization of the mononuclear $\mathrm{Cu}$-containing Aspergillus japonicus quercetin 2,3-dioxygenase reveals dramatic changes upon anaerobic binding of substrates. Eur. J. Biochem., 269 : 2971-2979.

Letouzey R. 1985. Carte phytogéographique du Cameroun au 1/500000 n ${ }^{0} 4$. IRAICIV, Université de Toulouse, France. 240p.

Makam ND. 2003. Etude phytochimique d'une plante antipaludique utilisée au Mali : spilanthesoleracea Jacq. (Asteraceae). Thèse de Doctorat. Université de Bamako, Mali, 78p.

Makumbelo E, Lukoki L, Paulus JJSJ, Luyindula N. 2008. Stratégie de valorisation des espèces ressources des produits non ligneux de la savane des environs de Kinshasa: II. Enquête ethnobotanique (aspects médicinaux). Tropicultura, 26: 129-134.

Marfak. 2003. Radiolyse gamma des flavonoïdes. Etude de leur réactivité avec les radicaux issus des alcools : formation de depsides. Thèse de Doctorat, Université de Limoge. 199p.

Minato K, Miyake Y. 2003. Lemon flavonoid, eriocitrin, suppresses exercise-induced oxidative damage in rat liver. Life Sci., 72: 1609-1616.

Mpondo Mponde E, Dibong SD, Ladoh YCF, Priso RJ, Ngoye A. 2012. Les plantes à phénols utilisées par les populations de la ville de Douala. Journal of Animal \&Plant Sciences, 15: 2083-2098.

Mullenders W. 1954. La position phytogéographique des hauts plateaux belges. Vegetatio, 5-6: 112-119.

Muthu C, Ayyanar M, Raja N, Ignacimuthu S. 2006. Medicinal plants used by traditional healers in Kancheepuram District of Tamil Nadu, India. Journal of Ethnobiology and Ethnomedicine, 2: 4269-4310.

Nawwar M, Ayoub N, Hussein S, Hashim A, El-Sharawy R, Wende K, Harms M, Lindequist U. 2012. Flavonol triglycoside and investigation of the antioxidant and cell stimulating activities of Annona muricata Linn. Archives of Pharmacal Research, 35: 761-767.

Ouattara D. 2006. Contribution à l'inventaire des plantes médicinales significatives utilisées dans la région de Divo (sud forestier de la Côte-d'Ivoire) et à la diagnose du poivrier de Guinée : Xylopia aethiopica (Dunal) A. Rich. (Annonaceae). Thèse de Doctorat de l'Université de Cocody-Abidjan, Côted'Ivoire, 184p.

Qian H, Nihorimbere V. 2004. Antioxidant power of phytochemicals from Psidium guajava Leaf. J. Zhejiang Univ. Sci., 5: 676-683.

Priso RJ, Nnanga JF, Etame J, Din N, Amougou A. 2011. Les produits forestiers non ligneux d'origine végétale: valeur importance dans quelques marchés de la région du littoral-Cameroun. J. Appl. Biosci., 40: 2715-2726.

Port B. 2007. Recherche bioguidée de molécules antipaludiques d'une plante

Guyanaise Piperhostmannianum var. berbicense. Thèse de Doctorat, Université de Toulouse, France, 249 p.

Skiloba D, Smith CM. 2000. Toxicical effect of flavonoids in organism. Am. J. Clin. Nutr., 70: 133-141.

Tchatat M, Ndoye O. 2006. Etude des produits forestiers non ligneux d'Afrique centrale : réalités et perspectives. Bois et Forêts des Tropiques, 288 : 27-39. 
Teissedre PL. 2005. Effets Physiologiques possibles d'une consommation modérée de vin pour diverses pathologies chroniques de l'homme: arthérosclérose, diabète, hypertension, cancer. Université de Montpellier, Faculté de Pharmacie, Sciences pour l'œnologie, 24p.

Ulanowska K, Traczyk A, Konopa G, Wegrzym G. 2006. Differential antibacterial activity of genistein arising from global inhibition of DND, RNA and protein synthesis in some bacterial strains. Arch. Microbiol., 184: 271-278.

Vita JA. 2005. Polyphenols and cardiovascular disease: effects on endothelial and platelet function. Am. J. Clin. Nutr. 81: 292S-297S.

Welch CR. 2010. Chemistry and pharmacology of kinkéliba (Combretum micranthum), a west african medicinal plant. $\mathrm{PhD}$ thesis, The State University of New Jersey, USA. 268 p.
White F. 1986. La végétation de l'Afrique. Mémoire accompagnant la carte de végétation de l'Afrique, Unesco/Aetfat/ Unso. 384 p.

WHO. 2010. International Statistical Classification of Diseases and Related Health Problems. 10th Revision. Instruction manual vol 22010 Edition. WHO, Geneva. 199p.

Yinyang J, Mpondo Mpondo E, Tchatat M, Ndjib RC, Mvogo Ottou PB, Dibong SD. 2014. Les plantes à alcaloïdes utilisées par les populations de la ville douala (Cameroun). Journal of Applied Biosciences, 78: 6600 - 6619 .

Zerbo P, Millogo-Rasolodimby J, NacoulmaOuedraogo OG, Van Damme P. 2007. Contribution à la connaissance des plantes médicinales utilisées dans les soins infantiles en pays San, au Burkina Faso. Int. J. Biol. Chem. Sci., 1: 262-274. 